\title{
Participação social e relações de poder na política sobre drogas no Piauí
}

Social participation and power relations in Piaui's drug policy

\author{
Thaís de Andrade Alves Guimarães* \\ Lucia Cristina dos Santos Rosa**
}

\begin{abstract}
Resumo - Este artigo apresenta um recorte da tese de doutorado ${ }^{1}$ que objetiva analisar a participação social dos atores que discutem e indicam caminhos para a implantação da política sobre drogas no contexto piauiense no período de 2005 a 2019. Trata-se de uma pesquisa analítica, descritiva, de abordagem qualitativa. Foram entrevistados representantes do Conselho Estadual de Políticas sobre Drogas (CEPD), gestores, profissionais que atuaram no campo álcool e drogas, além de usuários e representantes dos movimentos sociais. Os resultados da pesquisa sinalizam para a crescente transferência da construção e implementação da política sobre drogas, no contexto piauiense, para as organizações não governamentais, que hegemonizam o CEPD, definindo sua pauta, centralizada pela dimensão do tratamento. A relação de forças internas do CEPD sinaliza para sua baixa inovação política; porém, vários segmentos internos e externos, sobretudo de usuários, vêm lutando, fora dos espaços do CEPD, para alterar a direção do processo.

Palavras-chave: participação social; política pública; drogas; Piauí.
\end{abstract}

\begin{abstract}
This paper is an excerpt of a doctoral thesis and deals with the social participation of key players who discuss and steer the implementation of drug policies in Piaui from 2005 to 2019. It is an analytical and descriptive study, based on a qualitative research. Interviews were made with representatives of the State Council for Drug Policies (CEPD), including managers, professionals who worked with
\end{abstract}

\footnotetext{
* Assistente Social da Universidade Federal do Oeste da Bahia (UFOB); Doutora em Políticas Públicas pela Universidade Federal do Piauí (UFPI); Mestra em Prevenção e Assistência a Usuários de Álcool e Outras Drogas pelo Hospital de Clínicas de Porto Alegre/Universidade Federal do Rio Grande do Sul (HCPA/UFRGS). E-mail: thais.guimaraes@ufpi. edu.br. ORCID: https://orcid.org/0000-0002-3667-1813.

** Professora Titular do Departamento de Serviço Social e do Programa de Pós-Graduação em Políticas Públicas da Universidade Federal do Piauí (UFPI). Assistente Social. Pós-Doutora em Saúde Coletiva pela Universidade Estadual de Campinas (UNICAMP); Doutora em Serviço Social pela Universidade Federal do Rio de Janeiro (UFRJ) e Doutora em Sociologia pela Universidade Federal de Pernambuco (UFPE). Bolsista de Produtividade em Pesquisa nível 2 (PQ2) do CNPQ. E-mail: luciacrosa@ufpi.edu.br ORCID: https://orcid.org/0000-0003-2612-2981.

1 Tese de doutorado "A participação social na política de álcool e outras drogas no contexto piauiense no período de 2005 a 2019: relação de forças, consensos e tensionamentos" defendida no Programa de Pós-Graduação em Políticas Públicas (PPGPP) da Universidade Federal do Piauí (UFPI), indicada para concorrer ao Prêmio CAPES de Tese 2021.
} 
alcohol and drug dependance, as well as drug users and representatives of social movements. The research results point to the increasing transfer of drug policy creation and implementation in Piaui to nongovernmental organizations, which hegemonize CEPD, defining its agenda, centralized by the dimension of treatment. CEPD's internal strengths point to its poor political innovation; however, several internal and external segments, especially drug users, have been fighting outside CEPD spaces to change the direction of the process.

Keywords: social participation; public policy; drugs; Piaui.

\section{Introdução}

A participação social é um dos princípios orientadores das ações das políticas sociais, ganhando institucionalidade com a Constituição Federal (BRASIL, 1988), que organiza a seguridade social a partir do tripé: saúde, previdência e assistência social. A primeira, sendo a única política universal, implementada desde então pelo Sistema Único de Saúde (SUS), é regulamentada pela Lei Orgânica da Saúde no 8.080 (BRASIL, 1990a), que estabelece como instâncias colegiadas as conferências de saúde e os conselhos de saúde, e pela Lei no 8.142 (BRASIL, 1990b, p. 1), que:

Dispõe sobre a participação da comunidade na gestão do SUS, mediante a representação de vários segmentos da sociedade, através da figura do conselheiro da saúde, com $50 \%$ representando o segmento de usuários; $25 \%$ representando o governo e prestadores de serviço e $25 \%$ representando profissionais de saúde.

De modo geral, a participação da sociedade civil ocupou um legítimo espaço com a criação e ampliação das instâncias deliberativas e propositivas, como fóruns e conselhos gestores, de modo que as denominações de participação comunitária e participação popular cedem lugar ao conceito de participação social, ancorado na ideia de construção da cultura cívica. A participação social pressupõe comunidades influentes, compostas de organizações autônomas da sociedade civil, atuantes, fomentadoras de espírito público, na perspectiva de relações sociais igualitárias e estruturas solidificadas na confiança e na colaboração, articuladas em redes horizontais. Já a "participação cidadã" é fincada na universalização dos direitos sociais, na concepção do papel do Estado, sendo concebida como intervenção social periódica e planejada, caracterizada pela tendência à institucionalização, a partir da "criação e implementação de novas estruturas de representações, compostas por pessoas eleitas diretamente pela sociedade civil e por representantes do poder público" (GOHN, 2001, p. 57).

Ao tempo em que a população era evocada para participar do processo de controle social, houve alastramento do pensamento dominante 
em considerá-la incapaz e sem as habilidades necessárias para ocupação desses espaços. $\mathrm{E}$, assim, massifica-se uma cultura de prevalecimento do conhecimento técnico e científico nessas instâncias (CARVALHO; TEIXEIRA, 2017). Contudo, o contexto de "consolidação" democrática se processa em prol do fortalecimento da vocalização das necessidades sociais pelos próprios demandatários das políticas públicas. Paralelamente, observa-se, contraditoriamente, a tendência dos governantes em transferir as responsabilidades na primazia da execução da mesma para entes do terceiro setor ${ }^{2}$, que é crescentemente estimulado a se fortalecer, primeiramente através da criação de um marco regulatório para o setor, e, em seguida, pelas transferências de recursos orçamentários para tais entes.

Nesse contexto fica evidenciada a construção e reorientação da política de saúde mental, álcool e outras drogas como uma arena de disputas entre atores sociais que encarnam projetos e perspectivas distintas (SOUZA, 1984). Estes atores demarcam esse polêmico campo e atuam na inclusão de determinadas questões na agenda pública, igualmente na formulação, implementação e avaliação dos rumos dessa política.

Parte-se da premissa de que, historicamente, as políticas sociais sobre drogas do Estado brasileiro tenderam a influenciar a conformação e a ação dos seus atores sociais, com interesses distintos, quer pelas lacunas, principalmente assistenciais, quer por políticas deliberadas. As políticas proibicionistas, que orientaram a gênese da política sobre drogas e se tornaram hegemônicas, pautadas na segurança pública, tenderam a criminalizar o consumidor de substâncias psicoativas. Isso, de um lado, criou lacunas assistenciais e também participativas, sobretudo na política de saúde, que incorpora, inicialmente, esse segmento de maneira restrita à dimensão curativa, com sua participação limitada à dupla condição de "viciado infrator". Ou seja, é uma pessoa com marcas estigmatizadas, portanto, com barreiras explicitamente impostas à vocalização direta das suas diversas necessidades e visão de mundo, com tendência ao silenciamento. Segundo Rosa e Guimarães (2020), esse paradigma proibicionista dominante percorre um caminho seletivo, pois, ao focar no produto, criminaliza a pobreza interseccionada por marcadores de classe, raça e gênero; no entanto, essa concepção é tensionada pela redução de danos.

Nesse horizonte, algumas das lacunas assistenciais foram potencializadas/cobertas por entidades da sociedade civil, que também focaram, predominantemente, em ações curativas (de "recuperação", "reabilitação"), fundamentadas em um "espírito salvacionista", que tendeu a vocalizar as necessidades dos consumidores de substâncias psicoativas, inseridos no registro da caridade/benemerência. Com as conquistas das lutas sociais no processo de redemocratização, foram incorporadas ações sob o signo da

\footnotetext{
${ }^{2} \mathrm{O}$ terceiro setor engloba uma diversidade de instituições, que, sem ser o Estado e o mercado, não têm fins lucrativos e dependem, para sua sustentabilidade, de doações e de ações voluntárias, em tempo e dinheiro.
} 


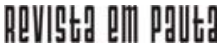

\} PARTICIPAÇÃO SOCIAL - GUIMARÃES, T. A. A.; ROSA, L. C. S. \}

DOI: $10.12957 /$ REP.2022.63526

cidadania e direitos humanos, como a política de redução de danos, construindo outras possibilidades de os consumidores de substâncias psicoativas serem reconhecidos como atores sociais, sujeitos de direitos, o que se forjou em outra relação de forças, favoráveis à construção da política sobre drogas com, e não para, o usuário. Mas, contraditoriamente, a assunção de políticas neoliberais, que restringe gastos sociais, focaliza a atenção em segmentos impedidos de acessar a satisfação de necessidades via mercado e se orientam para a privatização, seletividade, focalização e, consequentemente, reforço ao silenciamento dos demandatários das políticas sociais, limitados a "consumidores" de bens e serviços e estimulados à cultura do favor e da gratidão.

Ao se debruçar sobre a realidade do Conselho Estadual de Políticas sobre Drogas no Piauí, depara-se com uma realidade que diverge da perspectiva democrática posta pela legislação e o contexto de conquistas sociais em geral, haja vista ser composto majoritariamente por representantes governamentais e prestadores de serviços, sobretudo representação de comunidades terapêuticas, que ocupam o lugar destinado regimentalmente para a "sociedade civil", sem que o usuário direto da assistência ou suas entidades se façam representar. Tal fato redunda no predomínio da abordagem proibicionista dominante sobre drogas, que imperou como exclusiva até 1990, quando passa a ser tensionada por outra perspectiva: a de redução de danos.

Mesmo com um governante reconhecido como de esquerda, do Partido dos Trabalhadores, acelerou-se a transferência da implementação das políticas sociais para a "sociedade civil", com intenso fomento orçamentário, acompanhado de crescente desinvestimento nos equipamentos públicos. Nesse cenário, os atores sociais passam a disputar o fundo público, e, em um contexto como o piauiense, há uma delegação da construção do desenho da política sobre drogas para a "sociedade civil", cujo Conselho Estadual de Políticas sobre Drogas foi apropriado, inclusive numericamente, por representantes das comunidades terapêuticas desde sua gênese.

\section{Metodologia}

Trata-se de uma pesquisa descritiva, exploratória e analítica, de abordagem qualitativa, com base na triangulação de métodos e fontes. Foram entrevistadas 16 pessoas, que, pelo lugar que ocupam/ocuparam, possuem/possuíam informações estratégicas e fundamentais para contemplar os objetivos da pesquisa, sobretudo, conselheiros, técnicos, gestores, além dos representantes dos movimentos sociais, apontados pela técnica bola de neve.

Foram entrevistados sete representantes governamentais que integram/integraram o CEPD. Como representantes da sociedade civil e integrantes do CEPD, foram entrevistadas três pessoas selecionadas com a pers- 
pectiva de diversificação de participantes. Ainda como representante da sociedade civil, mas não integrantes do CEPD, foram entrevistados seis participantes.

Das entrevistas submetidas à análise de conteúdo na perspectiva de Minayo (2011), emergiram dois temas, subdivididos em sete categorias: (i) política pública sobre drogas: política pública e política social; paradigmas proibicionistas e redução de danos; trajetória histórica da política sobre drogas no Brasil e no Piauí; e (ii) participação social: dimensões históricas e conceituais; atores; caracterização e projetos; relação de forças; pautas das atas do CEPD.

As informações construídas foram analisadas à luz do método crítico-dialético de Marx, contextualizando aspectos importantes, como a historicidade e as contradições no movimento histórico inscrito na correlação de forças entre os sujeitos sociais que formulam, implementam e avaliam tal política, para que fosse possível extrair uma visão de totalidade dos fenômenos.

Vale destacar que esta pesquisa obedeceu criteriosamente às exigências do Comitê de Ética em Pesquisa com Seres Humanos, conforme Resolução no 466/2012 e 510/2016, do Conselho Nacional de Saúde, sendo submetida à Plataforma Brasil para aprovação do Comitê de Ética da Universidade Federal do Piauí (CEP/UFPI), com o Caee no 15231319.9.0000.5214.

\section{Os atores sociais em cena sob a hegemonia das comunidades terapêuticas}

No escopo da representação do Conselho Estadual de Políticas sobre Drogas (CEPD), a "sociedade civil" é reduzida às comunidades terapêuticas, instituições caracterizadas como sendo organizações não governamentais. Logo, há uma apropriação e um monopólio desse espaço por um grupo de interesse claramente identificado e caracterizado. Tais entes têm em comum a denominação CT, mas são plurais (CAVALCANTE, 2019), tanto no discurso, quanto nas orientações, muitas vezes distintos - embora algumas ações, tais como o fomento ao voluntariado, e, no caso dessas entidades, o caráter segregador, seja igualmente partilhado. A maioria tem um caráter religioso; todavia, há também aquelas vinculadas às políticas públicas, como mostra Rita Cavalcante (2019) a partir da pesquisa do Ipea. Entretanto, no Piauí, todas as CTs são exclusivamente de natureza religiosa. Em alguns territórios, configuram-se na esfera pública como espaço contraditório, que pode fortalecer as políticas públicas e o direito social, assim como pode contribuir para o contrário, para desuniversalizar direitos e privatizar ações estatais, retirando as insígnias de conquistas históricas ao prestar serviços como doações/benesses, fomentando a "gratidão" dos "beneficiados". 
Então, localizam-se em espaços de disputas por projetos societários. Com avanços e intensificação de políticas orientadas pelo ideário neoliberal, como esclarece Machado (2010, p. 272), "atualmente as ONGs tornaram-se o ator principal na negociação com o Estado, o que acarretou enfraquecimento dos movimentos sociais, deslocando a lógica das lutas e das reivindicações para o caminho da parceria e da negociação", configurando-se atualmente como o agente central da interlocução nas políticas sociais.

O produto da ação de parte significativa dessas instituições, até pelo seu interesse direto ao fundo público, no geral, desconfigura o direito social, quando alicerçado no discurso humanitário, na caridade. Tal direcionamento é muito comum de se observar na maioria das comunidades terapêuticas, predominando no CEPD, pois os "internos", ou seja, as pessoas atendidas, são consideradas como moralmente fracas, "sem caráter", comumente pecadores e não cidadãos/ãs, sujeitos/as de direitos. As ONGs têm papel central no "novo" trato da questão social, sobretudo por sua tendência em desresponsabilizar o Estado como principal agente da proteção social, buscando transfigurar o direito universal conquistado a duras penas, através da atividade filantrópica/caritativa/voluntária. Como esclarece Montaño (2014, p. 86), as ONGs têm um claro direcionamento ideológico, assumindo a condição de porta-vozes dos interesses sociais, em uma lógica que é "funcional às mudanças operadas pelo projeto neoliberal".

A paridade prevista na composição de um conselho de políticas públicas é completamente distorcida em relação ao que é posto na legislação. Na prática e no regimento do CEPD, é traduzida como: 50\% órgãos governamentais e 50\% "organizações não governamentais", uma interpretação muito singular desse órgão. Ou seja, os $25 \%$ de segmentos de gestores e prestadores de serviços públicos foram transformados em 50\% gestores $+50 \%$ prestadores de serviços públicos, esses últimos considerados como ONGs ou terceiro setor. Os 50\% de representação de usuários e 25\% de profissionais de saúde e trabalhadores em serviços de saúde são completamente extirpados, retirando, inclusive, as entidades corporativas/de classe.

Logo, explicitamente, o regimento do CEPD não atende ao preceito da Lei no $8.142 / 1990$, assim como exclui muitas entidades, pois exige um mínimo de três anos de funcionamento para se candidatar como representação da sociedade civil. Como chegar a essa paridade, com a criminalização histórica dos usuários e todo processo de desqualificação social que cercou e cerca esse segmento, que tem dificuldade em assumir publicamente seu consumo, se organizar e, consequentemente vocalizar suas necessidades coletivamente? Na direção do que analisa Leal (2006, p. 191), a paridade não se resume a um problema numérico: "Implica também a correlação de forças, luta pela hegemonia, alianças que devem-se estabelecer para consolidar os projetos e as propostas de encaminhamento no âmbito dos conselhos". 
Como visto, $50 \%$ dos membros são relacionados às organizações não governamentais e membros da "sociedade civil", reduzida a CTs. A legislação trata da representação de usuários, mas não conta com pessoas que se identifiquem diretamente como usuárias; exclusivamente, é uma democracia representativa e não substantiva. Aliás, no geral, os gestores/ coordenadores de comunidades terapêuticas admitem ter sido consumidores de substâncias psicoativas, porém, no âmbito do CEPD, sua condição fundese, mas também prevalece a condição de prestador de serviços. São componentes da sociedade civil, e, muitas vezes, usam da situação híbrida em que se encontram para manipular a dupla condição e avançarem em seus propósitos.

Consoante com a definição de estado ampliado na perspectiva gramsciana, observa-se que os conselhos, de fato, constituem-se em espaços de alargamento da participação social, forjando uma nova relação de forças, heterogênea, pois traz atores que até então eram desconhecidos nessa arena para vocalizar diretamente sua visão de mundo, tornando-se esfera de mediação de conflitos de interesses e pactuação social. Os conselhos seriam, portanto, espaços vivos de democracia representativa nos quais a sociedade civil (representada no geral por entidades) poderia interpelar o governante. Entretanto, há limites para a democracia direta, muito embora as reuniões do CEPD sejam abertas, todos podendo delas participar, com direito à voz, mas sem direito ao voto.

Segundo Wanderley e Raichelis (2004), o desafio da apropriação do que é público encontra-se na consolidação do real acesso e participação ativa dos sujeitos, em que a primazia é o interesse de todos, superando as marcas históricas do Estado brasileiro, o qual ainda seleciona grupos para a participação nas decisões, ações e rumos do país. Em seu significado normativo, o conceito de público, de acordo com os autores, remete ao interesse de todos e ao reconhecimento do direito de todos à participação na coisa pública; isso interpela a sociedade, e não apenas o Estado. Portanto, não é possível pensar o público sem a atuação conjunta Estado/sociedade, o que exige superar essa dicotomia.

É imprescindível essa defesa no campo das políticas públicas, já que são necessidades sociais reguladas e prestadas pelo Estado, e devem partir de demandas concretas, que se configuram no âmbito das lutas sociais. Vale ressaltar que a coisa pública é construída com recursos advindos de toda a população e a ela é preciso retornar, não somente na forma material, mas também imaterial, materializada na participação, como forma de socializar, de distribuir a riqueza socialmente produzida e de ampliar visões de mundo, contemplando a real diversidade que compõe a sociedade civil.

Embora as políticas públicas sejam de competência do Estado, não são decisões impositivas e injunções do governo para a sociedade, mas envolvem relações de reciprocidade e antagonismo entre essas duas esferas. Assim sendo, mesmo considerando a primazia do Estado na 


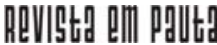

\} PARTICIPAÇÃO SOCIAL - GUIMARÃES, T. A. A.; ROSA, L. C. S. \}

DOI: $10.12957 /$ REP.2022.63526

condução das políticas públicas, a participação ativa da sociedade civil nos processos de definição e controle da sua execução é fundamental para a consolidação da sua dimensão efetivamente pública (WANDERLEY; RAICHELIS, 2004). Logo, ao se considerar o público estatal, é preciso integrar, no cotidiano de suas atividades, desde o planejamento até a execução e a participação dos diferentes atores sociais, a fim de que esses vocalizem suas necessidades e exerçam o controle social. As ações prestadas à população devem atender às necessidades sociais, considerando as particularidades de cada território e segmento.

É consenso na literatura que a esfera pública é concebida como inerente à democracia, cujo princípio organizativo está jungido à liberdade de expressão, contendo dimensões políticas e culturais, espaço aberto no qual se exprimem todos aqueles que se autorizam a falar publicamente. Outros autores também definem a esfera pública como "o espaço democrático onde os problemas sociais e as demandas da sociedade civil são tematizados e podem ser incluídos na agenda política" (OLIVEIRA; PINHEIRO, 2010, p. 2459).

Nesse sentido, a esfera pública é uma construção social, não é algo estático, tampouco acabado, e sim permeado de contradições e tensionamentos, não agregando somente grupos de interesses homogêneos; o que deve prevalecer é a defesa do interesse de todos, diversamente representados, enquanto espaço e entes/sujeitos de direitos. Para isso, Estado e sociedade não se sobrepõem em momento algum, ao contrário, atuam simultaneamente.

Assim, a homogeneidade dada no CEPD-PI viola o sentido da esfera pública, obstando o lugar de fala da multiplicidade de vozes que constitui a sociedade brasileira e a piauiense. Deste modo, defender o ente público é fortalecer a ação do Estado para o enfrentamento das manifestações da questão social, com a participação ativa da sociedade civil, que deve apresentar suas demandas, a partir de uma perspectiva do coletivo. Assim, os desafios impostos à construção dos espaços públicos, no Brasil, perpassam a relação democrática entre Estado e sociedade civil e a busca pelo enfrentamento da questão social, bem como o fortalecimento dos espaços de participação social (WANDERLEY; RAICHELIS, 2004). Além disso, é importante criar outras relações internas ao próprio CEPD, de ampliação de vozes, representações e abertura para mudanças e inovações.

Logo, em termos de participação social, desde a fase inicial de inclusão do tema álcool e outras drogas na agenda pública local e dos primeiros esboços da elaboração de uma política estadual, os representantes das comunidades terapêuticas (ONGs) intensificam sua presença e gestões, na perspectiva de cobrir lacunas do poder público (BRASIL, 2004) na atenção ao público consumidor prejudicial AD, buscando influenciar a direção da política, como admite um representante da gestão: 
Desenhamos a política estadual e as comunidades terapêuticas vieram participar dela para discutir e demandar do Estado auxílio para suas estruturações. (Representante governamental).

Como reconhecido acima, desde o início prevaleceram interesses secundários aos dos usuários diretos da assistência, posto que se impôs a necessidade de priorização de apoio para estruturação das CTs pelo poder público, em uma explícita ação instrumental em relação à coisa pública, o que denota que nem tinham pré-condições mínimas para prestação do serviço. Então, parece haver, por parte de algumas CTs, uma maquiagem, isto é, uma falsa aparência de que estão equipadas e apresentam melhores condições do que os equipamentos do serviço público para desenvolver ações com esse heterogêneo e complexo público, que consome SPA de diferentes maneiras, por distintas razões, em diferentes contextos e circunstâncias, tendo a mesma função singular para cada consumidor. Entretanto, oferecem respostas padronizadas, únicas, muitas vezes associadas às violações de direitos humanos. Tal perspectiva, obviamente, leva à estruturação legal para endossar essa representação majoritária no regimento do CEPD, o que é justificado em nome de uma democracia formal/procedimental, que leva em conta apenas os procedimentos legais (BIELSCHOWSKY, 2011) que nem sempre se orientam por critérios de justiça e que persistem na trajetória histórica:

Hoje tem uma maioria de conselheiros de comunidade terapêutica. (Representante governamental).

O CEPD está totalmente desequilibrado, hoje ele parece uma central das unidades de tratamento, não existe uma paridade. (Representante da sociedade civil).

Embora numericamente ainda seja insignificante, há várias forças políticas e perspectivas de abordagens em curso no estado do Piauí, como visto, com vozes abafadas no interior do CEPD. Há a representação da redução de danos muito associada às Raps, mas, também, ao tratamento comunitário, com ações de prevenção e promoção em saúde. Entretanto, há predomínio do modelo proibicionista, representado nas CTs e nas ações dos órgãos de repressão, como o Pelotão Mirim e o Programa Educacional de Resistência às Drogas e à Violência (Proerd).

Há lutas políticas para reverter esse quadro, inclusive no interior do próprio CEPD, o que implica mudança na relação de forças, até para se consignar alterações legislativas, para pluralizar a representação da sociedade civil e a partilha de poder concentrado, o que constitui esfera de resistências, pois quem está no poder procura manter o status quo:

Não posso negar e é conhecido que existe uma resistência em relação à abertura de espaço para outras instituições que represente esse 
seguimento mais heterogêneo. Agora, isso poderia ser resolvido pela legislação. Há 6 meses atrás nós colocamos no Diário Oficial uma comissão específica pra fazer a alteração que a gente chama de adequação da legislação estadual e do regimento interno [...], desse período pra cá existe uma resistência pra isso. Então a comissão não se reuniu e agora entrei recentemente na comissão e a intenção nossa deliberada em ata é fazer essa alteração porque isso implica naturalmente no dia das eleições, inclusive na eleição nossa anterior o Conselho de Psicologia entrou com uma representação e a eleição foi nula. E tivemos que fazer outro processo, justamente, por conta de que para que o próprio processo seja legítimo. Mas a lei estadual e o regimento interno deixam muito vago em relação a isso. E existe o interesse e é bom que se saiba das instituições não governamentais nem participarem deste conselho, mas o regimento é tímido, por isso ele deixa muitas brechas ou então ele não consegue garantir a participação dessas outras entidades e o resultado hoje é esse. (Representante governamental).

Se existe o conselho estadual sobre drogas na sua composição, esse $50 \%$ de usuários, eles deviam vir dessas instituições que tomam frente, da Homo Lobus, da Âncora, da Fênix, ou de outro modelo. Quando você se propõe a fazer parte do conselho, o próprio conselho tem que diversificar da parte da gestão, da parte dos profissionais, da parte dos usuários. Então acho que o que está faltando é a maior participação do usuário que defende esse olhar, redução de danos, de modelo de Caps, digamos, até mesmo das instituições NA, AA, importante que essas pessoas pudessem participar desse conselho porque fortalecia, pois a grande dificuldade dos conselhos é ser composto por pessoas que não estão alinhadas com o programa de fato. (Representante da sociedade civil).

Dessa forma, a luta política abrange várias dimensões, inclusive legislativa, para incorporação de novas entidades, que possam renovar a arena de discussões e direcionamentos da política de álcool e drogas no plano local, pluralizando o debate e as alternativas. Afinal, constitui atribuição principal do CEPD a formulação da política sobre drogas do Estado, não para um ente específico, as CTs. Logo, excluir as vozes de outras instituições, sobretudo dos representantes de trabalhadores da Raps e de usuários, constitui ação antidemocrática, pois exclui minorias, ferindo o princípio da tolerância à pluralidade (BIELSCHOWSKY, 2011). Mas antes da mudança legal em si, há que se construir uma outra relação de forças, para constituir um grupo contra-hegemônico ao dominante, ou seja, os representantes das CTs. Como explícito acima, já há indícios em prol desse movimento contra-hegemônico internamente ao CEPD, embora seja um segmento minoritário. Como visto, forças externas também podem interferir no processo e contribuir no redirecionamento.

Nesse contexto, as práticas de participação tanto podem alterar como reproduzir a cultura política tradicional (OLIVEIRA; PINHEIRO, 


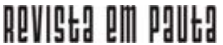

\} PARTICIPAÇÃO SOCIAL - GUIMARÃES, T. A. A.; ROSA, L. C. S. \}

DOI: $10.12957 /$ REP.2022.63526

2010). Há tensionamentos, contudo, poucas forças acumuladas em prol de mudanças substantivas, o que sinaliza para a manutenção da elite dominante, que busca manter a hegemonia do paradigma proibicionista. Essa política elege a "recuperação"/tratamento como foco/eixo dos trabalhos, impedindo que a diversidade de modelos e ofertas de alternativas que contemplem as particularidades de distintos públicos, para além do desenho de comunidades terapêuticas, expressem-se, ampliem-se e ganhem sustentação política e até mesmo financeira, como expresso na fala de um dos entrevistados:

Na política passada, ela nunca andou direito porque um segmento se fortaleceu, que é o segmento de recuperação, capitaneado por uma federação que oprimiu os outros, oprimia mesmo. Então criouse briga com o Conselho do Serviço Social, com o Conselho de Psicologia, e quem fazia redução de danos não tinha voz, nem vez. E quando eu digo que vem essa gestão e tem um olhar bem aberto pra isso. Qual é o retrocesso agora? É que o segmento criou força de novo, porque no segmento de comunidade terapêutica, via de regra, se chegou à abstinência total, e é meio que sufocante para as outras instituições, pro cara que tem a escolinha de música, pro cara que tem uma escolinha de futebol, que trabalha prevenção, pra ele é mais sufocante, embora a gestão estadual tenha um bom olhar. (Representante da sociedade civil - grifo nosso).

Minoria quer fazer uma política de prevenção, e a grande maioria quer apenas receber o dinheiro do governo, através das Cendrogas [...]. As CTs deveriam ter consciência que precisamos de outras representações: da prevenção, da redução de danos, dos conselhos de classes, mas não, eles querem dominar tudo como se o conselho fosse deles. (Representante da sociedade civil).

Desta forma, o projeto dominante se impõe, oprimindo a expressão das minorias e fundamentando-se no paradigma da redução de danos, materializado em ações de prevenção baseadas no esporte (futebol), na arte (música), na cultura, dentre outros. Interessante que foi observado, nas entrevistas, que mesmo entre alguns representantes das CTs há segmentos favoráveis ao voto e apoio das ações dos representantes do segmento minoritário, redução de danos. Essa observação é importante em termos de possíveis avanços e ganhos, sobretudo em termos de alianças políticas; reconhecer esse grupo e com ele se articular, afinal, em uma perspectiva gramsciana:

As batalhas devem ser travadas inicialmente no âmbito da sociedade civil, visando à conquista de posições e espaços ('guerra de posição'), da direção político-ideológica e do consenso dos setores majoritários da população à guisa de ampliação e consolidação de acesso ao poder de Estado. (COUTINHO, 1989, p. 89). 


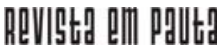

\} PARTICIPAÇÃO SOCIAL - GUIMARÃES, T. A. A.; ROSA, L. C. S. \}

DOI: $10.12957 /$ REP.2022.63526

Apostar que o grupo dominante deveria ter consciência cívica que precisamos de outras representações sinaliza para a possibilidade de integrantes desse segmento terem uma leitura ampliada da esfera pública. Mas a materialidade dessa consciência, com certeza, ameaça o projeto dominante, especialmente em um contexto de escassez de recursos financeiros, parte significativa dos quais retirados da Raps/SUS, que historicamente foi subfinanciada e, na atual conjuntura, é desfinanciada e até transferida para o terceiro setor.

Com a inclinação posta, o CEPD torna-se voz uníssona do modelo remanicomializante representado pelas CTs, sufocando tendências orientadas para a prevenção, promoção em saúde, redução de danos e direitos humanos, flexibilizando a abordagem na direção do caminhar do próprio consumidor, que não consegue, não pode ou não deseja manterse abstinente. Entretanto, observa-se, no discurso de alguns coordenadores de CTs, a apropriação de conceitos do paradigma contrário, como prevenção, promoção e redução de danos, na perspectiva de sinalizar que também intervêm ou pretendem intervir a partir desses eixos de atuação do CEPD. Ou seja, também se lançam no jogo político do campo do "adversário", com várias intencionalidades, inclusive a de ampliar o leque de financiamento de suas ações e borrar diferenças demarcatórias e ideopolíticas.

Nessa relação interativa, decisões das CTs tendem a ser orientadas, no plano local, predominantemente, pela lógica do favor, pela benevolência/caridade/voluntariado, que perpassam as deliberações e os sentimentos, sem que o bem comum/coletivo, a heterogeneidade e a complexidade do público, bem como as situações e necessidades, sejam mais investidas. Assim, não há fortalecimento da democracia nem da esfera pública. No âmbito do CEPD, forja-se um enclave no qual o sentido da remanicomialização da política se destaca pela própria predominância do modelo proibicionista e segregador, representado nas concepções e ações desses representantes.

Observa-se que os conselhos de classe, que representam os profissionais, sobretudo de psicologia, Serviço Social e OAB, que são os mais citados pelos participantes da pesquisa - até porque os dois primeiros têm um claro posicionamento político a favor da redução de danos -, têm empreendido lutas para alterar a relação de forças dominante. Há, portanto, uma ação interna e externa para pluralizar a representação da sociedade civil e quebrar com o monopólio da representação das comunidades terapêuticas, que fazem com que seus interesses e perspectivas prevaleçam nas pautas do CEPD, isso é, na agenda de prioridades de discussão e do jogo político do desenho da política sobre drogas no Estado do Piauí, consequentemente, da definição dos rumos da distribuição orçamentária e nos assuntos a serem discutidos e deliberados.

Mas, como visto, mudanças implicam alterar substancialmente o regimento, que divide a representação entre "sociedade civil", reduzida a 


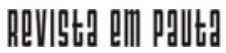

\} PARTICIPAÇÃO SOCIAL - GUIMARÃES, T. A. A.; ROSA, L. C. S. \}

DOI: $10.12957 /$ REP.2022.63526

ONGs, e representação governamental. Porém, acima de tudo, é preciso mudar o jogo político, a relação de forças em prol da diversificação de representação de outros grupos e perspectivas, na direção de uma efetiva esfera pública.

\section{Considerações finais}

No Brasil e, consequentemente, no Piauí, apesar da cultura de submissão ainda presente, e mais fortemente identificada nos usuários de saúde mental e em contexto de consumo de substâncias psicoativas, os conselhos ocupam um importante papel no fomento da participação social e na defesa dos direitos. Têm como base as associações de usuários e familiares, que fomentam o protagonismo, a formação política e a crítica propositiva aos rumos da política sobre drogas no plano local. A ampliação da participação dos usuários permite a produção de conhecimentos e aprendizados coletivos, que proporcionam um novo fazer do controle social. Além disso, promovem a emancipação dos usuários como sujeitos históricos e sociais capazes de vocalizar as próprias necessidades, sem tutela, de tomar suas próprias decisões, de transformar a realidade local e de se transformar, na direção da democracia substantiva.

O desafio é, portanto, a criação de espaços verdadeiramente públicos, que permitam a descrição plural do mundo e a construção da agenda política, a partir da fala dos sujeitos múltiplos/diversos. Isso abre novos horizontes para a invenção política efetivamente/substantivamente democrática, bem como para a elaboração de novas propostas e alternativas de construção de uma sociedade mais justa e igualitária, uma vez que são postos em discussão e deliberação aspectos relevantes da vida dos sujeitos.

Essa discussão é fundamental para entender a essência do Estado na garantia de direitos aos cidadãos através das políticas públicas; além disso, reflete sobre a importância da organização e participação social como espaços de luta permanente por conquista, ampliação e efetivação de direitos para novos segmentos sociais.

A correlação de forças entre os diferentes atores é dinâmica, construída no embate das lutas sociais e, muitas vezes, configurando-se como pontual. Observou-se que dentro de um mesmo segmento é comum não haver consensos, pois foram explicitadas situações em que representantes da "sociedade civil" se aliaram com as ONGs, com o intuito de se contraporem ao segmento. Muito embora a orientação das CTs seja na mesma direção, há grupos em seu interior que apoiam ações de prevenção e modelo mais aberto/comunitário, sendo favoráveis, portanto, à pluralização da esfera pública. Então, a correlação de forças é dinâmica e se constrói conforme a pauta e as possibilidades de aliança, em cada conjuntura histórica. 


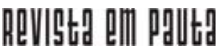

\} PARTICIPAÇÃO SOCIAL - GUIMARÃES, T. A. A.; ROSA, L. C. S. \}

DOI: $10.12957 /$ REP. 2022.63526

Como visto, há dois cenários principais de participação social dos atores: o cenário do CEPD e o extraCEPD. No CEPD, a participação pende para a burocratização e a falta de vitalidade, havendo, anualmente, pautas que se repetem, sem inovações. Os atores que atuam fora do CEPD têm produzido algumas mudanças bem efetivas nas leis, na qualidade da participação e em serviços.

No Piauí, observou-se que as ações do grupo contra-hegemônico ainda são pouco articuladas entre si, necessitando maior investimento, seja através da criação de um fórum ou colegiado, para fazer face à tendência hegemônica e também para difundir e articular mais suas ações, muito embora observe-se a criação de endereços virtuais e atuação via ciberativismo. 


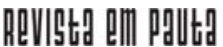

\} PARTICIPAÇÃO SOCIAL - GUIMARÃES, T. A. A.; ROSA, L. C. S. \}

DOI: $10.12957 /$ REP.2022.63526

\section{Referências}

BRASIL. Constituição da República Federativa do Brasil. Brasília: Senado Federal, 1988.

BRASIL. Lei n. 8080, de 19 de setembro de 1990. Dispõe sobre as condições para a promoção, proteção e recuperação da saúde, a organização e o funcionamento dos serviços correspondentes e dá outras providências. Brasília, Diário Oficial, 1990a.

BRASIL. Casa Civil. Lei n. 8.142, de 28 de dezembro de 1990. Dispõe sobre a participação da comunidade na gestão do Sistema Único de Saúde (SUS) e sobre as transferências intergovernamentais de recursos financeiros na área da saúde e dá outras providências. Brasília, Diário Oficial, 1990b.

BRASIL. Ministério da Saúde. Diretrizes para a política de atenção integral aos usuários de álcool e outras drogas. In: BRASIL. A política do Ministério da Saúde para atenção integral a usuários de álcool e outras drogas. Brasília, v. 2., ed. rev. ampl., 2004.

CARVALHO, P.; TEIXEIRA, S. M. A política de assistência social brasileira e os sentidos da autonomia, protagonismo e participação social. In: TEIXEIRA, S. M.; MACEDO, J. P. S. Políticas sociais na contemporaneidade: programas, serviços e trabalho. Teresina: EDUFPI, 2017.

CAVALCANTE, R. A institucionalização clínica e política das comunidades terapêuticas e a sua relação com a saúde mental brasileira. In: VASCONCELOS, E. M.; CAVALCANTE, R. (Org.). Religiões e o paradoxo apoio social: intolerância e implicações na política de drogas e comunidades terapêuticas. São Paulo: Hucitec, 2019.

COUTINHO, C. N. Gramsci: um estudo sobre seu pensamento político. Rio de Janeiro: editora Campus, 1989.

GOHN, M. da G. M. Conselhos gestores e participação sociopolítica. São Paulo: Cortez, 2001.

LEAL, F. X. Conselhos municipais antidrogas: entre o sonho e ar realidade. Dissertação (Mestrado em Política Social) - Ufes, Vitória, 2006, mimeo.

MACHADO, G. S. O Serviço Social nas ONGs no campo da saúde: projetos societários em disputa. Revista Serviço Social e Sociedade, 2010.

MINAYO, M. C. de S. O desafio do conhecimento: pesquisa qualitativa em saúde. São Paulo: Hucitec, 2011.

MONTAÑO, C. O lugar histórico e o papel político das ONGs. In: MONTAÑO, C. (Org.). O canto da sereia: crítica à ideologia e aos projetos do "terceiro setor". São Paulo: Cortez, 2014. 


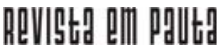

\} PARTICIPAÇÃO SOCIAL - GUIMARÃES, T. A. A.; ROSA, L. C. S. \}

DOI: 10.12957/REP.2022.63526

OLIVEIRA, L. C.; PINHEIRO, R. A participação nos conselhos de saúde e sua interface com a cultura política. Ciência e Saúde Coletiva, v. 15, n. 5, 2010.

BIELSCHOWSKY, R. M. Democracia procedimental e democracia substantiva: entre um relativismo axiológico absoluto e um absolutismo axiológico relativo. In: ENCONTRO NACIONAL DO CONPEDI, 20. Anais. Belo Horizonte, 22, 23,25 jul. 2011.

ROSA, L. C. dos S; GUIMARÃES, T. A. A. O racismo na/da política proibicionista brasileira: redução de danos como antídoto antirracista. Revista Em Pauta, v. 18, 2020. Disponível em: https://www.e-publicacoes.uerj.br/ index.php/revistaempauta/article/view/47204. Acesso em: 9 maio 2021.

SOUZA, H. J. Como se faz análise de conjuntura. Petrópolis: Vozes, 1984.

WANDERLEY, L. E. W.; RAICHELIS, R. Desafios de uma gestão pública democrática na integração regional. Revista Serviço Social e Sociedade, São Paulo, n. 78, 2004.

DOI: $10.12957 /$ rep.2022.63526

Recebido em 25 de junho de 2021.

Aprovado para publicação em 15 de outubro de 2021.

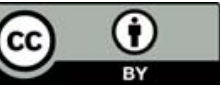

A Revista Em Pauta: Teoria Social e Realidade Contemporânea está licenciada com uma Licença Creative Commons Atribuição 4.0 Internacional. 